\title{
Clinical Characteristics of a Non-Alcoholic Fatty Liver Disease Population Across the Fibrosis Spectrum Measured by Magnetic Resonance Elastography: Analysis of Screening Data
}

\author{
Grit Andersen (D) - Leona Plum-Mörschel · Paul D. Hockings • \\ Anni Morsing $\cdot$ Mads S. Palle $\cdot$ Olivia Svolgaard $\cdot$ Anne Flint
}

Received: July 29, 2020 / Accepted: September 11, 2020 / Published online: October 1, 2020

(c) The Author(s) 2020

\begin{abstract}
Introduction: Non-alcoholic fatty liver disease (NAFLD), one of the most common liver diseases, is associated with liver-related complications and metabolic comorbidities. The phenotype is wide, ranging from simple steatosis to non-alcoholic steatohepatitis with advanced fibrosis. In this analysis of a phase 1 trial, clinical characteristics of screened subjects with NAFLD were studied according to the
\end{abstract}

\author{
G. Andersen ( $\square)$ \\ Project Development, Profil, Neuss, Germany \\ e-mail: Grit.Andersen@profil.com \\ L. Plum-Mörschel \\ Profil, Mainz, Germany \\ P. D. Hockings \\ Antaros Medical, BioVenture Hub, 43183 Mölndal, \\ Sweden \\ P. D. Hockings \\ MedTech West, Chalmers University of Technology, \\ Gothenburg, Sweden
}

A. Morsing · O. Svolgaard

Medical and Science, Obesity and Metabolism,

Novo Nordisk A/S, Søborg, Denmark

M. S. Palle

Biostatistics, Global, Development, Novo Nordisk

A/S, Søborg, Denmark

A. Flint

Clinical Pharmacology and Translational Medicine,

Novo Nordisk A/S, Søborg, Denmark extent of fibrosis assessed using magnetic resonance elastography (MRE).

Methods: One hundred ninety-four subjects with body mass index (BMI) of $25-40 \mathrm{~kg} / \mathrm{m}^{2}$ and suspected NAFLD were assessed by MRE and grouped by MRE thresholds as a proxy for fibrosis staging (groups 0-4). Data were summarized by group levels, and correlation analyses between MRE values and clinical parameters (including magnetic resonance imaging-proton density fat fraction) were performed.

Results: Most subjects had MRE values in the lower range (groups $0-1 ; N=148$ ). Type 2 diabetes (T2D) and $\mathrm{BMI}>35 \mathrm{~kg} / \mathrm{m}^{2}$ were more frequent in groups with higher than lower MRE values. Subjects in the highest MRE groups also tended to be older and have higher liver enzyme concentrations compared with lower MRE groups. No, or weak, correlations were found between MRE values and clinical parameters (all $r$ values $\leq 0.45$ ).

Conclusions: There was considerable variation and overlap in clinical characteristics across the spectrum of liver stiffness. Although groups with high MRE values generally included more subjects with T2D and obesity, and had higher age and concentrations of liver enzymes, the clinical characteristics did not strongly correlate with MRE scores in this population.

Trial Registration: Registered on Clinicaltrials.gov on November 29, 2017 (NCT03357380). 
Keywords: Fibrosis; Magnetic resonance elastography; Non-alcoholic fatty liver disease

\section{Key Summary Points}

This study of subjects with non-alcoholic fatty liver disease looked at the clinical features of the subjects grouped according to the extent of their disease (liver stiffness).

Those with more advanced disease (greater stiffness of the liver) more often also had type 2 diabetes, obesity, liver enzyme abnormalities, or were of older age.

However, there was no clear association or correlation between the presence of liver disease and the clinical features of subjects.

\section{DIGITAL FEATURES}

This article is published with digital features, including a summary slide, to facilitate understanding of the article. To view digital features for this article go to https://doi.org/10.6084/ m9.figshare.12928817.

\section{INTRODUCTION}

Non-alcoholic fatty liver disease (NAFLD) represents the most common cause of liver disease and is estimated to affect approximately $25 \%$ of the adult population globally [1]. Type 2 diabetes (T2D) and obesity are among the strongest risk factors for NAFLD development, and as their prevalence increases, that of NAFLD is also expected to rise further [2]. NAFLD is classified into non-alcoholic fatty liver, which is characterized by simple hepatic steatosis, and the more advanced subtype, non-alcoholic steatohepatitis (NASH), where steatosis is accompanied by inflammation and ballooning [2]. Around one in four patients with NAFLD have $\mathrm{NASH}$, with the associated progressive hepatic fibrosis, cirrhosis, and hepatocellular carcinoma causing significant morbidity and mortality [3].

At present, lifestyle modification is the cornerstone of treatment for patients with NAFLD. Although many potential treatment modalities are in development, including glucagon-like peptide-1 receptor agonists (GLP-1RAs) approved for the treatment of T2D and obesity, no medical treatment options for NASH are currently approved [4].

Another key issue in patients with NAFLD is the differentiation of simple steatosis from inflammation (i.e., NASH) and advanced hepatic fibrosis. The use of biopsy, recognized as the gold standard, is limited by factors including its invasive nature, sampling bias, and risk of complications [5]. Magnetic resonance (MR) elastography (MRE) can non-invasively determine liver stiffness, a surrogate marker for assessing liver fibrosis, via analysis of shear waves induced in the liver by low-frequency vibrations applied to the abdominal wall $[6,7]$. Indeed, MRE has been shown to predict fibrosis in patients with NAFLD, with high diagnostic accuracy $[3,6,7]$. In a pooled analysis of individual participant-level data $(n=232)$, MRE was able to discriminate any fibrosis (stage 1, area under the receiver-operating curve [AUC] 0.86), significant fibrosis (stage 2, AUC 0.87), advanced fibrosis (stage 3, AUC 0.90), and cirrhosis (stage 4, AUC 0.91) [8].

A trial investigated the effect of semaglutide, a GLP-1RA given by subcutaneous injection, on liver fibrosis assessed by MRE and other parameters in subjects with NAFLD. In the current analysis, the clinical characteristics of screened subjects from the trial were studied across groups, based on the extent of fibrosis assessed using MRE.

\section{METHODS}

This analysis was conducted as part of a randomized, double-blind, placebo-controlled, parallel-group, phase 1 trial that investigated the effects of subcutaneous treatment with semaglutide versus placebo on liver fibrosis as assessed by MRE (ClinicalTrials.gov identifier, NCT03357380). Effects on MR imaging-proton 
density fat fraction (MRI-PDFF) and other aspects of NAFLD were also assessed. The trial protocol was approved by relevant local independent ethics committees (Neuss: Ethics Committee, Medical Association of North Rhine; Mainz: Ethics Committee, State Medical Association of Rhineland-Palatinate; reference 2017273). This trial is being conducted in accordance with the Declaration of Helsinki and International Council for Harmonisation of Technical Requirements for Pharmaceuticals for Human Use. All subjects provided written informed consent before any trial-related activities were initiated.

The current analysis included all subjects with evaluable MRE data in the screening population of the phase 1 study, including subjects who did not meet the eligibility criteria of the parent study. Eligibility criteria for the phase 1 study included: $18-75$ years of age, body mass index (BMI) $25-40 \mathrm{~kg} / \mathrm{m}^{2}$, liver stiffness $2.50-4.63 \mathrm{kPa}$ (inclusive) measured by MRE, and liver steatosis $\geq 10 \%$ measured by MRI-PDFF. Subjects with or without T2D were eligible. Key exclusion criteria included documented causes of chronic liver disease other than NAFLD (including NASH), known or suspected abuse of alcohol, and glycated hemoglobin $\left(\mathrm{HbA}_{1 \mathrm{c}}\right)>9.5 \%$. MR assessments were conducted using a Siemens 1.5T MR imaging (MRI) scanner. MRE scans were acquired in four axial slices following $4 \mathrm{~h}$ of fasting and in accordance with the Quantitative Imaging Biomarkers Alliance guidelines [9]. Briefly, the passive driver was placed over the right lower chest wall at the level of the xiphisternum in the midclavicular line. Regions of interest were drawn at least $1 \mathrm{~cm}$ inside the liver boundary, avoiding areas of incoherent waves, and contained a minimum of 500 pixels per slice. Liver fat content was assessed using MRI-PDFF over the entire liver.

The demographics and clinical characteristics of the screened subjects were recorded and blood samples collected. Alanine aminotransferase (ALT), aspartate aminotransferase (AST), alkaline phosphatase (ALP), gamma-glutamyl transferase (GGT), $\mathrm{HbA}_{1 \mathrm{c}}$, total bilirubin, highsensitivity C-reactive protein (hsCRP), and international normalized ratios (INRs) were measured. Fibrosis-4 score (FIB-4; based on patient age, platelet count, AST, and ALT [10]) and NAFLD fibrosis score (NFS; based on patient age, BMI, platelet count, AST to ALT ratio, albumin, and the presence of diabetes/impaired glucose tolerance [11]) were calculated. Kaya et al. [12] have previously advised that FIB-4 and NFS scores have an acceptable diagnostic performance in the exclusion of advanced fibrosis in patients with normal or elevated transaminases. FIB- 4 scores of $<1.3$ and $>2.67$ indicate a low and high risk for advanced fibrosis, respectively $[13,14]$; NFS $<-1.455$ indicates that advanced fibrosis is unlikely, but a score $\geq 0.67$ indicates a high probability of fibrosis [11].

To investigate possible patterns in the demographics, body measurements, or other clinical parameters across the MRE-based fibrosis spectrum, the subjects were categorized into five groups (0-4), according to MRE thresholds of $<2.61, \quad 2.61-2.96,2.97-3.61, \quad 3.62-4.69$, and $\geq 4.70 \mathrm{kPa}$, respectively. Groupings were based on data from the study by Hsu et al., where both MRE and corresponding confirmatory biopsies for fibrosis stage (FO-F4) were available [15]. Geometric mean and coefficient of variation were presented for subject characteristics and clinical parameters, unless otherwise specified. Comparison of MRE with other biomarkers on a continuous scale, instead of categorizing them, results in preservation of more data information. Therefore, to assess any possible correlation between MRE and age, BMI, ALT, AST, GGT, NFS, FIB-4, MRI-PDFF, and $\mathrm{HbA}_{1 \mathrm{c}}$ (for subjects with and without T2D separately), data were plotted and a Spearman correlation coefficient calculated.

\section{RESULTS}

A total of 194 subjects in the screening population of the phase 1 trial had evaluable MRE data and were thus included in this analysis. Liver-related characteristics measured by MR and grouped by liver stiffness are shown in Table 1 . There was a high number of subjects in groups 0 and 1 ( $n=82$ and $n=66$, respectively) compared with groups $2-4(n=21, n=14$, and $n=11$, respectively). Mean values for liver steatosis by MRI-PDFF generally increased 
Table 1 Liver-related characteristics measured by magnetic resonance

\begin{tabular}{|c|c|c|c|c|c|}
\hline \multirow[t]{2}{*}{ Characteristic } & \multicolumn{5}{|c|}{ Liver stiffness measured by MRE } \\
\hline & $\begin{array}{l}\text { Group } 0 \\
(<2.61 \mathrm{kPa}) \\
n=82\end{array}$ & $\begin{array}{l}\text { Group } 1 \\
(2.61-2.96 \mathrm{kPa}) \\
n=66\end{array}$ & $\begin{array}{l}\text { Group } 2 \\
(2.97-3.61 \mathrm{kPa}) \\
n=21\end{array}$ & $\begin{array}{l}\text { Group } 3 \\
(3.62-4.69 \mathrm{kPa}) \\
n=14\end{array}$ & $\begin{array}{l}\text { Group } 4 \\
(\geq 4.70 \mathrm{kPa}) \\
n=11\end{array}$ \\
\hline \multicolumn{6}{|l|}{$\begin{array}{c}\text { Liver stiffness } \\
\text { MRE, } \mathrm{kPa}\end{array}$} \\
\hline $\begin{array}{l}\text { Geometric mean } \\
(\mathrm{CV})\end{array}$ & $2.3(7.9)$ & $2.8(3.6)$ & $3.2(4.9)$ & $4.0(6.7)$ & $5.3(17.3)$ \\
\hline \multicolumn{6}{|l|}{$\begin{array}{l}\text { Liver steatosis } \\
\text { MRI-PDFF, \% }\end{array}$} \\
\hline $\begin{array}{l}\text { Geometric mean } \\
(\mathrm{CV})\end{array}$ & $11.9(87.9)$ & $13.5(69.4)$ & $13.7(87.3)$ & $13.1(77.2)$ & $14.2(100.6)$ \\
\hline
\end{tabular}

$C V$ coefficient of variation, $M R E$ magnetic resonance elastography, $M R I-P D F F$ magnetic resonance imaging-proton density fat fraction

slightly across MRE groups, from $11.9 \%$ in group 0 to $14.2 \%$ in group 4 .

The demographics and clinical parameters by liver stiffness groups are shown in Table 2 . The majority of subjects $(62.2-81.0 \%)$ in all groups were male. The highest mean (standard deviation) age and BMI were observed in group 3 (63.0 [9.6] years and $34.6[3.6] \mathrm{kg} / \mathrm{m}^{2}$, respectively) and group 4 (61.8 [9.4] years and $34.5[4.5] \mathrm{kg} / \mathrm{m}^{2}$, respectively). In line with this, groups 3 and 4 had the greatest proportion of subjects with $\mathrm{BMI}>35 \mathrm{~kg} / \mathrm{m}^{2}$ compared with groups $0-2$ (42.9-54.5\% in groups 3 and 4 vs. $25.8-35.4 \%$ in groups $0-2$ ). The highest prevalence of T2D was also seen in subjects in groups 3 and 4 (>90\%) compared with groups 0-2 $(<77 \%)$. ALT, AST, and GGT levels generally increased with liver stiffness from group 0-4, although groups 2 and 3 were similar. Group 4 showed the highest geometric mean of $41.7 \mathrm{U} / \mathrm{l}, 39.0 \mathrm{U} / \mathrm{l}$, and $86.8 \mathrm{U} / \mathrm{l}$ for ALT, AST, and GGT levels, respectively. There was no apparent trend across groups 0-4 for levels of ALP, total bilirubin, hsCRP, INR, or systolic or diastolic blood pressure.

Small differences were observed across the groups for both FIB-4 and NFS, but mean values for both parameters generally increased with increasing MRE group. For FIB-4, the geometric mean values ranged from 1.1 in group 0 to 1.9 in group 4 , and $3.6 \%$ of subjects were categorized as being at high risk of advanced fibrosis. For NFS, mean values ranged from -1.2 in group 0 to 0.2 in group $4 ; 10.3 \%$ of subjects were considered at high risk of advanced fibrosis based on their NFS.

Scatter plots and the Spearman correlation coefficient of clinical parameters and MRE values are shown in Fig. 1. The Spearman correlation coefficient between MRE values and age $(r=0.07)$, BMI $(r=0.07)$, ALT $(r=0.16)$, AST $(r=0.20)$, NFS $(r=0.24)$, FIB-4 score $(r=0.18)$, and MRI-PDFF ( $r=0.07)$ showed no or very weak correlations. Weak correlations were observed between MRE values and $\mathrm{HbA}_{1 \mathrm{c}}$ for subjects without T2D $(r=0.45)$ and GGT $(r=0.34)$. There was no correlation between $\mathrm{HbA}_{1 \mathrm{c}}$ and MRE values in subjects with T2D $(r=0.05)$.

\section{DISCUSSION}

The screened cohort with evaluable MRE data presented a broad spectrum of NAFLD. Subjects in all five MRE-based fibrosis groups (0-4) were included, although most subjects (76\%) had low-level fibrosis (groups 0-1). We observed that subjects with more advanced group 3 or 4 
Table 2 Demographics and clinical parameters by liver stiffness measured by MRE

\begin{tabular}{|c|c|c|c|c|c|}
\hline \multirow[t]{2}{*}{ Characteristic } & \multicolumn{5}{|c|}{ Liver stiffness measured by MRE } \\
\hline & $\begin{array}{l}\text { Group } 0 \\
(<2.61 \mathrm{kPa}) \\
n=82\end{array}$ & $\begin{array}{l}\text { Group } 1 \\
(2.61-2.96 \mathrm{kPa}) \\
n=66\end{array}$ & $\begin{array}{l}\text { Group } 2 \\
(2.97-3.61 \mathrm{kPa}) \\
n=21\end{array}$ & $\begin{array}{l}\text { Group } 3 \\
(3.62-4.69 \mathrm{kPa}) \\
n=14\end{array}$ & $\begin{array}{l}\text { Group } 4 \\
(\geq 4.70 \mathrm{kPa}) \\
n=11\end{array}$ \\
\hline Male, $n(\%)$ & $51(62)$ & $46(70)$ & $17(81)$ & $10(71)$ & $7(64)$ \\
\hline \multicolumn{6}{|l|}{ Age group, years } \\
\hline$\geq 18$ to $<65, n(\%)$ & $59(72)$ & $42(64)$ & $12(57)$ & $5(36)$ & $6(55)$ \\
\hline$\geq 65$ to $<75, n(\%)$ & $23(28)$ & $24(36)$ & $9(43)$ & $9(64)$ & $5(46)$ \\
\hline Mean (SD) & $59.0(7.8)$ & $60.1(8.3)$ & $60.0(10.1)$ & $63.0(9.6)$ & $61.8(9.4)$ \\
\hline \multicolumn{6}{|l|}{ BMI, $\mathrm{kg} / \mathrm{m}^{2}$} \\
\hline$\geq 25$ to $<30, n(\%)$ & $10(12)$ & $5(8)$ & $4(19)$ & $1(7)$ & $2(18)$ \\
\hline$\geq 30$ to $<35, n(\%)$ & $43(52)$ & $44(67)$ & $10(48)$ & $7(50)$ & $3(27)$ \\
\hline$\geq 35$ to $<40, n(\%)$ & $29(35)$ & $17(26)$ & $7(33)$ & $6(43)$ & $6(55)$ \\
\hline Mean (SD) & $33.6(3.4)$ & $33.8(2.7)$ & $33.3(3.4)$ & $34.6(3.6)$ & $34.5(4.5)$ \\
\hline $\begin{array}{l}\text { Type } 2 \text { diabetes } \\
\text { mellitus, } n(\%)\end{array}$ & $44(54)$ & $47(71)$ & $16(76)$ & $13(93)$ & $10(91)$ \\
\hline \multicolumn{6}{|l|}{$\mathrm{HbA}_{1 \mathrm{c}}, \%$} \\
\hline $\begin{array}{l}\text { Type } 2 \text { diabetes, } \\
\text { mean }(\mathrm{SD})\end{array}$ & $7.2(0.9)$ & $7.2(1.1)$ & $7.3(0.8)$ & $7.5(1.1)$ & $7.3(1.1)$ \\
\hline $\begin{array}{l}\text { Non-type } 2 \text { diabetes, } \\
\text { mean }(\mathrm{SD})\end{array}$ & $5.5(0.3)$ & $5.8(0.3)$ & $5.9(0.6)$ & $5.4(-)$ & $5.8(-)$ \\
\hline \multicolumn{6}{|c|}{ Alanine aminotransferase, $U / 1$} \\
\hline $\begin{array}{l}\text { Geometric mean } \\
(\mathrm{CV})\end{array}$ & $29.1(50.5)$ & $33.5(54.9)$ & $32.7(56.8)$ & $27.1(54.3)$ & $41.7(44.6)$ \\
\hline \multicolumn{6}{|c|}{ Aspartate aminotransferase, $\mathrm{U} / 1$} \\
\hline Geometric mean $(\mathrm{CV})$ & $26.5(30.5)$ & $28.2(35.2)$ & $30.0(34.8)$ & $26.6(30.6)$ & $39.0(39.9)$ \\
\hline \multicolumn{6}{|l|}{ Alkaline phosphatase, U/l } \\
\hline $\begin{array}{l}\text { Geometric mean } \\
(\mathrm{CV})\end{array}$ & $66.4(28.0)$ & $73.9(23.1)$ & $77.9(31.3)$ & $65.6(18.7)$ & $69.4(26.9)$ \\
\hline \multicolumn{6}{|c|}{ Gamma-glutamyl transferase, U/l } \\
\hline $\begin{array}{l}\text { Geometric mean } \\
(\mathrm{CV})\end{array}$ & $31.1(63.1)$ & $36.0(69.1)$ & $46.7(76.0)$ & $40.3(61.9)$ & $86.8(49.4)$ \\
\hline \multicolumn{6}{|l|}{ Total bilirubin, $\mu \mathrm{mol} / \mathrm{l}$} \\
\hline $\begin{array}{l}\text { Geometric mean } \\
(\mathrm{CV})\end{array}$ & $8.3(45.6)$ & $7.3(46.2)$ & $7.1(58.4)$ & $7.0(47.7)$ & $8.6(37.6)$ \\
\hline
\end{tabular}


Table 2 continued

\begin{tabular}{|c|c|c|c|c|c|}
\hline \multirow[t]{2}{*}{ Characteristic } & \multicolumn{5}{|c|}{ Liver stiffness measured by MRE } \\
\hline & $\begin{array}{l}\text { Group } 0 \\
(<2.61 \mathrm{kPa}) \\
n=82\end{array}$ & $\begin{array}{l}\text { Group } 1 \\
(2.61-2.96 \mathrm{kPa}) \\
n=66\end{array}$ & $\begin{array}{l}\text { Group } 2 \\
(2.97-3.61 \mathrm{kPa}) \\
n=21\end{array}$ & $\begin{array}{l}\text { Group } 3 \\
(3.62-4.69 \mathrm{kPa}) \\
n=14\end{array}$ & $\begin{array}{l}\text { Group } 4 \\
(\geq 4.70 \mathrm{kPa}) \\
n=11\end{array}$ \\
\hline \multicolumn{6}{|c|}{ High-sensitivity C-reactive protein, mg/l } \\
\hline $\begin{array}{l}\text { Geometric mean } \\
(\mathrm{CV})\end{array}$ & $2.1(124.8)$ & $2.5(123.4)$ & $2.9(110.9)$ & $3.9(261.0)$ & $1.8(250.6)$ \\
\hline \multicolumn{6}{|l|}{ INR } \\
\hline $\begin{array}{l}\text { Geometric mean } \\
(\mathrm{CV})\end{array}$ & $1.0(6.0)$ & $1.0(7.0)$ & $1.0(6.1)$ & $1.1(7.4)$ & $1.1(6.5)$ \\
\hline \multicolumn{6}{|c|}{ Systolic blood pressure, $\mathrm{mmHg}$} \\
\hline Mean (SD) & $137.6(12.2)$ & $136.8(11.6)$ & $140.6(11.5)$ & $137.0(14.9)$ & $139.9(14.7)$ \\
\hline \multicolumn{6}{|c|}{ Diastolic blood pressure, $\mathrm{mmHg}$} \\
\hline Mean (SD) & $87.8(5.6)$ & $85.9(6.1)$ & $88.5(4.7)$ & $84.0(11.1)$ & $85.9(8.6)$ \\
\hline \multicolumn{6}{|l|}{ Fibrosis-4 score } \\
\hline $\begin{array}{l}\text { Geometric mean } \\
(\mathrm{CV})\end{array}$ & $1.1(36.4)$ & $1.3(45.5)$ & $1.2(36.8)$ & $1.3(55.5)$ & $1.9(30.7)$ \\
\hline \multicolumn{6}{|c|}{ NAFLD fibrosis score } \\
\hline Mean (SD) & $-1.2(1.1)$ & $-0.7(1.2)$ & $-1.0(1.2)$ & $-0.4(1.5)$ & $0.2(0.8)$ \\
\hline
\end{tabular}

$B M I$ body mass index, $C V$ coefficient of variation, $H b A_{1 c}$ glycated hemoglobin, $I N R$ international normalized ratio, $M R E$ magnetic resonance elastography, NAFLD non-alcoholic fatty liver disease, $S D$ standard deviation

fibrosis (13\%) had a higher prevalence of T2D and obesity and were older compared with subjects in groups $0-2$. Konerman et al. described a risk stratification approach to identify and differentiate subjects with high likelihood of NASH and fibrosis for clinical trials and, consistent with the current findings, listed advanced age, T2D, and obesity as important factors [4].

Genetically driven T2D and obesity have both been shown to causally increase the risk of NAFLD [16]. Advanced fibrosis (defined as $\mathrm{MRE} \geq 3.6 \mathrm{kPa}$ ) is common in T2D, occurring in $7.1 \%$ of 100 patients in a cross-sectional study [17]. T2D is a known independent predictor of advanced fibrosis in NAFLD [18], and the pathogenesis of diabetes and NAFLD is thought to be related to insulin resistance and hyperinsulinemia $[19,20]$. Studies have demonstrated a more aggressive course of NAFLD in diabetes and higher risk of cirrhosis in patients with T2D and NAFLD [21, 22].

As the value of MRI for elastography and PDFF determination is being increasingly demonstrated $[6-8,23-26]$, it is being used more widely in phase 1 and phase 2a studies to assess dynamic changes in liver stiffness and liver steatosis. MRI-PDFF has been shown to correlate strongly with hepatic fat assessed histologically in both adults and children [27, 28]. The correlation of MRI-PDFF with histologic steatosis was found to be stronger for higher fibrosis stages in children [28], and in the current analysis, MRI-PDFF increased with increasing liver stiffness.

In a meta-analysis to compare different methods to detect fibrosis in patients with NAFLD confirmed by biopsy, MRE and shear 
(a)

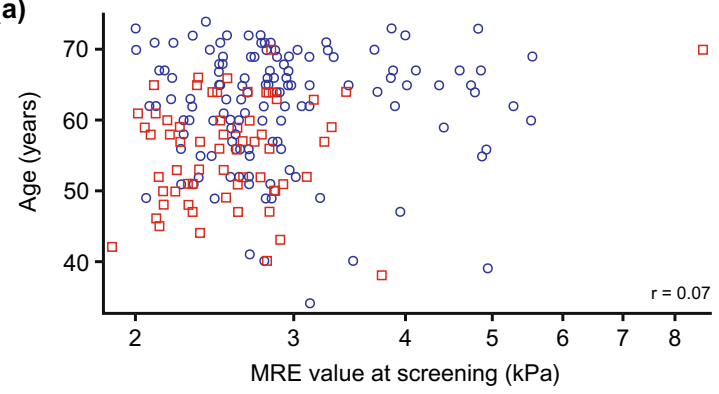

(c)

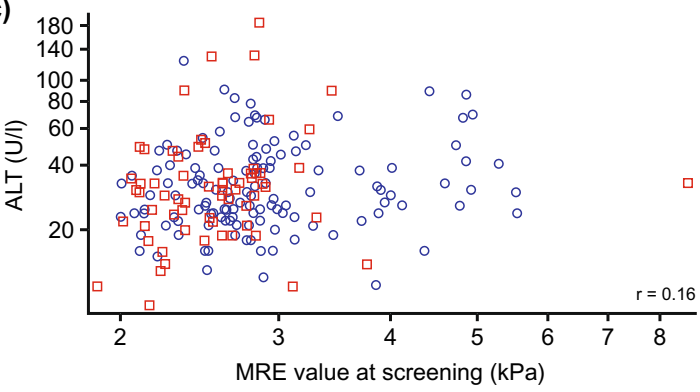

(e)

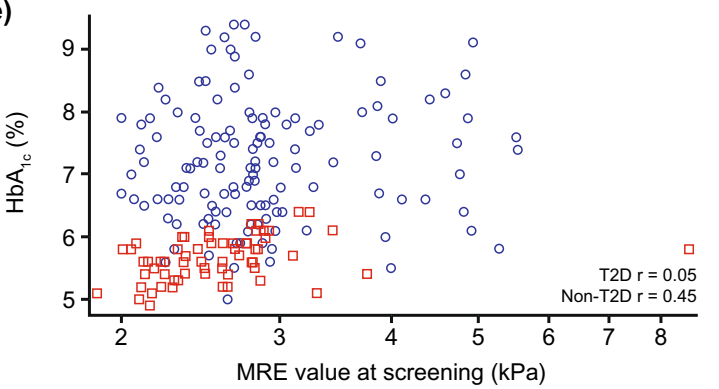

(g)

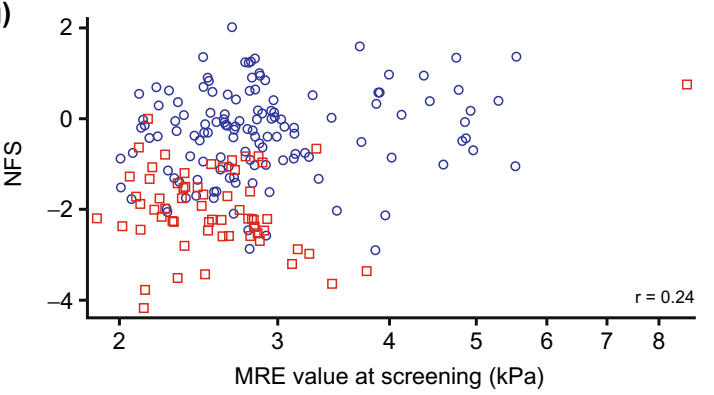

(i)

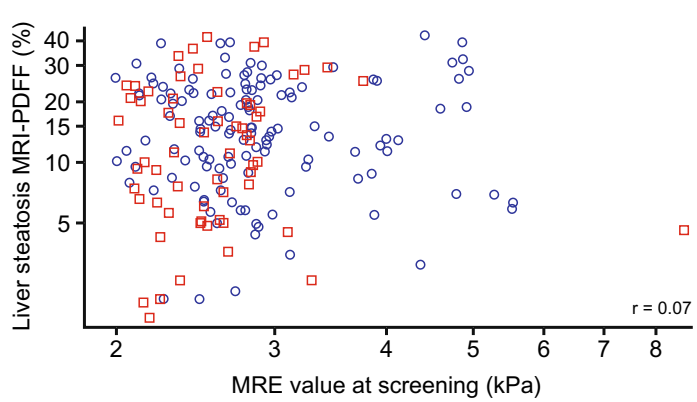

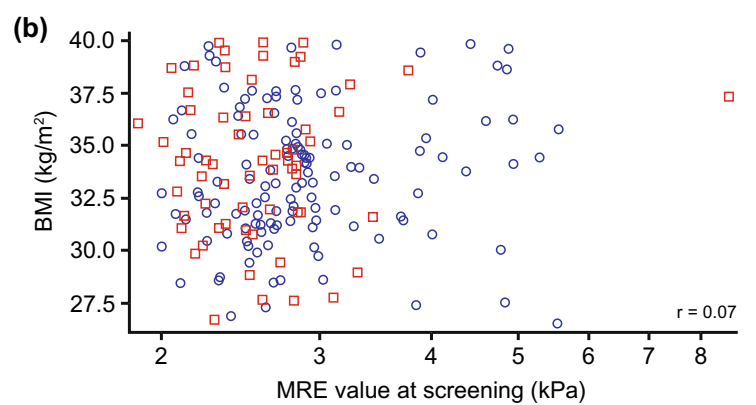

(d)
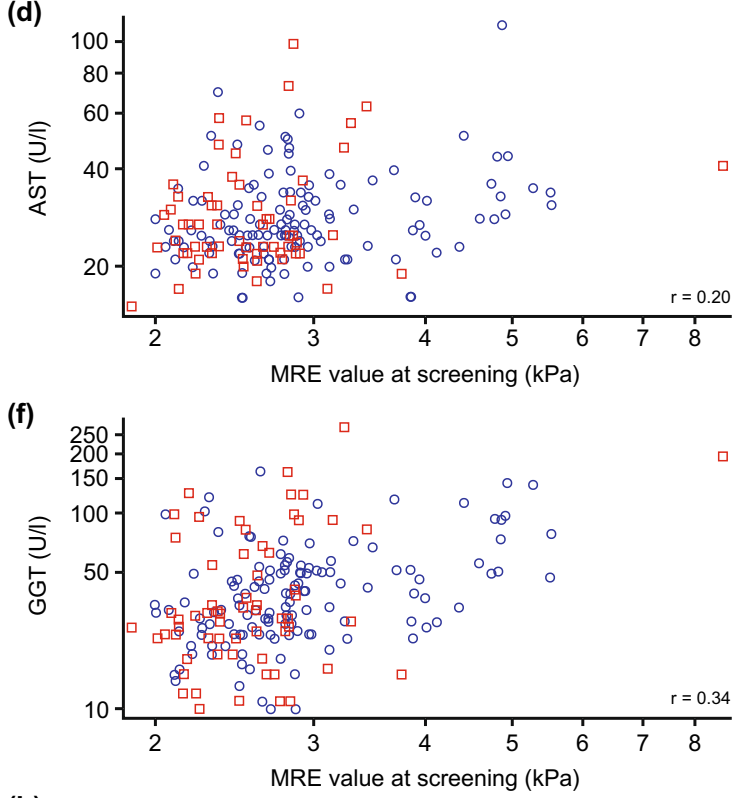

(h)

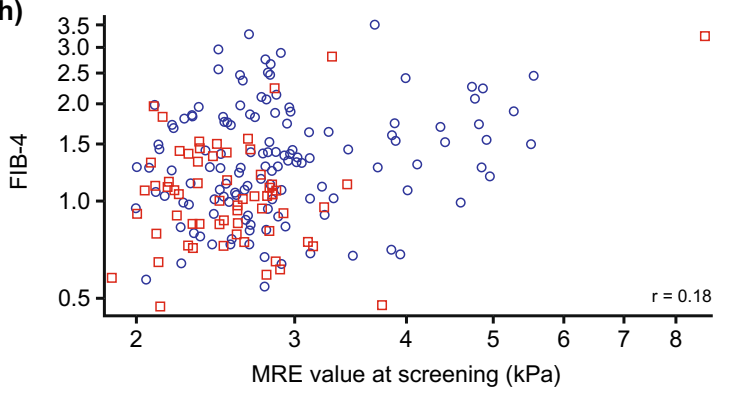


4Fig. 1 Scatter plots of age (a), BMI (b), ALT (c), AST (d), $\mathrm{HbA}_{1 \mathrm{c}}(\mathbf{e})$, GGT (f), NFS (g), FIB-4 (h), and MRI-PDFF (i) versus MRE values, and by presence/absence of T2D. $A L T$ alanine aminotransferase, $A S T$ aspartate aminotransferase, $B M I$ body mass index, FIB-4 fibrosis-4 score, GGT gamma-glutamyl transferase, $H b A_{1 c}$ glycated hemoglobin, $M R E$ magnetic resonance elastography, MRI-PDFF magnetic resonance imaging-proton density fat fraction, NFS non-alcoholic fatty liver disease fibrosis score, $T 2 D$ type 2 diabetes

wave elastography appeared to have the highest diagnostic accuracy for staging fibrosis [29]. Furthermore, MRE was found to be more accurate than ultrasound-based transient elastography for the identification of liver fibrosis (stage 1 or more) in a prospective cross-sectional study of $>100$ patients with NAFLD where biopsy analysis was the standard [30]. In the current ongoing trial, the MRE thresholds for each stage were the same as those proposed in a systematic review and pooled analysis from heterogenous populations [15]. Recently, in a longitudinal study, a $15 \%$ increase in liver stiffness on MRE was a predictor for an increased likelihood of histologic fibrosis progression as well as progression from early to advanced fibrosis [31]. Further validation of clinically relevant MRE thresholds is needed to enable MRE to be used more widely to diagnose and monitor fibrosis and response to treatment.

In the current study in groups 3 and 4, geometric mean FIB-4 was $\geq 1.3$, and mean NFS was $>-0.4$. Of the four laboratory non-invasive tests studied in the meta-analysis by Xiao et al. (NFS, FIB-4, aminotransferase to platelets ratio index, and BARD score), the best diagnostic performance for detecting advanced fibrosis was offered by NFS and FIB-4 [29]; however, it is known that they have limited diagnostic accuracy for lesser stages of fibrosis [31], which most subjects had in the present study.

Subjects in the groups with the highest MRE values were generally older and were more likely to have obesity and T2D in the current study, with no other distinct patterns observed across the liver stiffness spectrum. The data set showed considerable variability in clinical characteristics across the groups, with a weak upward trend observed between MRE-based liver stiffness groups and mean values of NFS and FIB- 4 and between MRE and concentrations of the liver enzymes, ALT, AST, and GGT. No or very weak-to-weak correlations were seen between MRE values and other clinical characteristics.

A limitation of this analysis is the relatively small number of subjects in groups 3 and 4 . Further studies with larger populations of patients with advanced fibrosis would help to confirm or refute any possible associations. In addition, liver biopsy data were not available to confirm the severity of fibrosis as this was beyond the scope of the phase 1 study and present analysis.

\section{CONCLUSIONS}

The present study showed a considerable variation and overlap in clinical characteristics across groups of increasing liver stiffness as a surrogate marker of liver fibrosis. In general, groups with the highest MRE values included subjects with greater prevalence of T2D and obesity, with higher age and values of liver enzymes, but the correlation analysis did not reveal any strong associations. Further investigations are warranted.

\section{ACKNOWLEDGMENTS}

We gratefully thank the trial participants and all personnel involved in the trial. We would like to acknowledge the research physicians and the clinical study team for their excellent work as well as the team from the MRI site at the Institute of Diagnostic and Interventional Radiology, Universitätsklinikum Frankfurt der Goethe-Universität, Frankfurt, Germany.

Funding. This trial was sponsored by Novo Nordisk A/S, Denmark. The sponsor, Novo Nordisk A/S, also funded the journal's Rapid Service and Open Access Fees. 
Medical Writing Assistance. The authors thank Anna Bacon of Articulate Science and Paul Barlass of Spirit Medical Communications Group Limited for medical writing and editorial assistance. Medical writing and editorial assistance was funded by Novo Nordisk A/S.

Authorship. All named authors meet the International Committee of Medical Journal Editors (ICMJE) criteria for authorship for this article, take responsibility for the integrity of the work as a whole, and have given their approval for this version to be published.

Authorship Contributions. Grit Andersen contributed to the trial conduct. Leona PlumMörschel contributed to the discussion of the trial design and trial conduct. All authors contributed to the drafting and review of the manuscript.

Disclosures. Grit Andersen reports grants from Novo Nordisk A/S during the conduct of the study. Leona Plum-Mörschel declares receiving speaker honoraria, travel grants, and fees from Novo Nordisk during the conduct of the study; and speaker honoraria and travel grants from Eli Lilly. Paul Hockings is an employee of Antaros Medical. Anni Morsing, Mads Sundby Palle, Olivia Svolgaard, and Anne Flint are employees of and report stocks from Novo Nordisk A/S.

Compliance with Ethics Guidelines. The parent phase 1 study was conducted in accordance with the principles stated in the Declaration of Helsinki and in line with the International Conference on Harmonisation Guidelines for Good Clinical Practice. The study protocol and any subsequent amendments were reviewed and approved by an independent ethics committee at each site (Neuss: Ethics Committee, Medical Association of North Rhine; Mainz: Ethics Committee, State Medical Association of Rhineland-Palatinate; reference 2017273). All subjects provided written informed consent to participate.

Data Availability. Data will be shared with bona fide researchers submitting a research proposal approved by the independent review board. Access request proposals can be found at novonordisk-trials.com. Data will be made available after research completion, and approval of the product and product use in the European Union and the USA. Individual participant data will be shared in data sets in a deidentified/anonymized format.

Open Access. This article is licensed under a Creative Commons Attribution-NonCommercial 4.0 International License, which permits any non-commercial use, sharing, adaptation, distribution and reproduction in any medium or format, as long as you give appropriate credit to the original author(s) and the source, provide a link to the Creative Commons licence, and indicate if changes were made. The images or other third party material in this article are included in the article's Creative Commons licence, unless indicated otherwise in a credit line to the material. If material is not included in the article's Creative Commons licence and your intended use is not permitted by statutory regulation or exceeds the permitted use, you will need to obtain permission directly from the copyright holder. To view a copy of this licence, visit http://creativecommons.org/licenses/by$\mathrm{nc} / 4.0 /$.

\section{REFERENCES}

1. Younossi ZM, Koenig AB, Abdelatif D, Fazel Y, Henry L, Wymer M. Global epidemiology of nonalcoholic fatty liver disease-meta-analytic assessment of prevalence, incidence, and outcomes. Hepatology. 2016;64:73-84.

2. Estes C, Anstee QM, Arias-Loste MT, Bantel H, Bellentani S, Caballeria J, et al. Modeling NAFLD disease burden in China, France, Germany, Italy, Japan, Spain, United Kingdom, and United States for the period 2016-2030. J Hepatol. 2018;69: 896-904.

3. Loomba R, Lim JK, Patton H, El-Serag HB. AGA clinical practice update on screening and surveillance for hepatocellular carcinoma in patients with nonalcoholic fatty liver disease: expert review. Gastroenterology. 2020;158:1822-30. 
4. Konerman MA, Jones JC, Harrison SA. Pharmacotherapy for NASH: current and emerging. J Hepatol. 2018;68:362-75.

5. Zhou JH, Cai JJ, She ZG, Li HL. Noninvasive evaluation of nonalcoholic fatty liver disease: current evidence and practice. World J Gastroenterol. 2019;25:1307-26.

6. Jayakumar S, Middleton MS, Lawitz EJ, Mantry PS, Caldwell SH, Arnold H, et al. Longitudinal correlations between MRE, MRI-PDFF, and liver histology in patients with non-alcoholic steatohepatitis: analysis of data from a phase II trial of selonsertib. J Hepatol. 2019;70:133-41.

7. Dulai PS, Sirlin CB, Loomba R. MRI and MRE for non-invasive quantitative assessment of hepatic steatosis and fibrosis in NAFLD and NASH: clinical trials to clinical practice. J Hepatol. 2016;65: 1006-16.

8. Singh S, Venkatesh SK, Loomba R, Wang Z, Sirlin C, Chen J, et al. Magnetic resonance elastography for staging liver fibrosis in non-alcoholic fatty liver disease: a diagnostic accuracy systematic review and individual participant data pooled analysis. Eur Radiol. 2016;26:1431-40.

9. Quantitative Imaging Biomarkers Alliance. QIBA Profile: Magnetic resonance elastography of the liver. 2018. https://qibawiki.rsna.org/images/a/a5/ MRE-QIBAProfile-2018-05-02-CONSENSUS.pdf. Accessed 3 Apr 2020.

10. Sterling RK, Lissen E, Clumeck N, Sola R, Corrêa MC, Montaner J, et al. Development of a simple noninvasive index to predict significant fibrosis in patients with $\mathrm{HIV} / \mathrm{HCV}$ coinfection. Hepatology. 2006;43:1317-25.

11. Angulo P, Hui JM, Marchesini G, Bugianesi E, George J, Farrell GC, et al. The NAFLD fibrosis score: a noninvasive system that identifies liver fibrosis in patients with NAFLD. Hepatology. 2007;45:846-54.

12. Kaya E, Bakir A, Eren F, Yilmaz Y. The utility of noninvasive scores in non-alcoholic fatty liver disease patients with normal and elevated serum transaminases. Hepatol Forum. 2020;1:8-13.

13. Kaya E, Bakir A, Kani HT, Demirtas CO, Keklikkiran C, Yilmaz Y. Simple noninvasive scores are clinically useful to exclude, not predict, advanced fibrosis: a study in Turkish patients with biopsyproven nonalcoholic fatty liver disease. Gut Liver. 2020;14:486-91.

14. Shah AG, Lydecker A, Murray K, Tetri B, Contos MJ, Sanyal AJ, et al. Comparison of noninvasive markers of fibrosis in patients with nonalcoholic fatty liver disease. Clin Gastroenterol Hepatol. 2009;7: 1104-12.

15. Hsu C, Caussy C, Imajo K, Chen J, Singh S, Kaulback K, et al. Magnetic resonance vs transient elastography analysis of patients with nonalcoholic fatty liver disease: a systematic review and pooled analysis of individual participants. Clin Gastroenterol Hepatol. 2019;17:630-7.

16. Liu Z, Zhang Y, Graham S, Wang X, Cai D, Huang $M$, et al. Causal relationships between NAFLD, T2D and obesity have implications for disease subphenotyping. J Hepatol. 2020;73:263-76.

17. Doycheva I, Cui J, Nguyen P, Costa EA, Hooker J, Hofflich $\mathrm{H}$, et al. Non-invasive screening of diabetics in primary care for NAFLD and advanced fibrosis by MRI and MRE. Aliment Pharmacol Ther. 2016;43:83-95.

18. Angulo P, Keach JC, Batts KP, Lindor KD. Independent predictors of liver fibrosis in patients with nonalcoholic steatohepatitis. Hepatology. 1999;30: 1356-62.

19. Marchesini G, Brizi M, Morselli-Labate AM, Bianchi G, Bugianesi E, McCullough AJ, et al. Association of nonalcoholic fatty liver disease with insulin resistance. Am J Med. 1999;107:450-5.

20. Sargin M, Uygur-Bayramiçli O, Sargin H, Orbay E, Yayla A. Association of nonalcoholic fatty liver disease with insulin resistance: is OGTT indicated in nonalcoholic fatty liver disease? J Clin Gastroenterol. 2003;37:399-402.

21. Adams LA, Harmsen $S$, St Sauver JL, Charatcharoenwitthaya P, Enders FB, Therneau T, et al. Nonalcoholic fatty liver disease increases risk of death among patients with diabetes: a community-based cohort study. Am J Gastroenterol. 2010;105:1567-73.

22. Younossi ZM, Gramlich T, Matteoni CA, Boparai N, McCullough AJ. Nonalcoholic fatty liver disease in patients with type 2 diabetes. Clin Gastroenterol Hepatol. 2004;2:262-5.

23. Cui J, Ang B, Haufe W, Hernandez C, Verna EC, Sirlin CB, et al. Comparative diagnostic accuracy of magnetic resonance elastography vs. eight clinical prediction rules for non-invasive diagnosis of advanced fibrosis in biopsy-proven non-alcoholic fatty liver disease: a prospective study. Aliment Pharmacol Ther. 2015;41:1271-80.

24. Kim D, Kim WR, Talwalkar JA, Kim HJ, Ehman R. Advanced fibrosis in nonalcoholic fatty liver disease: noninvasive assessment with MR elastography. Radiology. 2013;268:411-9. 
25. Loomba R, Wolfson T, Ang B, Hooker J, Behling C, Peterson $\mathrm{M}$, et al. Magnetic resonance elastography predicts advanced fibrosis in patients with nonalcoholic fatty liver disease: a prospective study. Hepatology. 2014;60:1920-8.

26. Tang A, Desai A, Hamilton G, Wolfson T, Gamst A, Lam J, et al. Accuracy of MR imaging-estimated proton density fat fraction for classification of dichotomized histologic steatosis grades in nonalcoholic fatty liver disease. Radiology. 2015;274: 416-25.

27. Middleton MS, Heba ER, Hooker CA, Bashir MR, Fowler KJ, Sandrasegaran K, et al. Agreement between magnetic resonance imaging proton density fat fraction measurements and pathologist-assigned steatosis grades of liver biopsies from adults with nonalcoholic steatohepatitis. Gastroenterology. 2017;153:753-61.

28. Middleton MS, Van Natta ML, Heba ER, Alazraki A, Trout AT, Masand P, et al. Diagnostic accuracy of magnetic resonance imaging hepatic proton density fat fraction in pediatric nonalcoholic fatty liver disease. Hepatology. 2018;67:858-72.

29. Xiao G, Zhu S, Xiao X, Yan L, Yang J, Wu G. Comparison of laboratory tests, ultrasound, or magnetic resonance elastography to detect fibrosis in patients with nonalcoholic fatty liver disease: a meta-analysis. Hepatology. 2017;66:1486-501.

30. Park CC, Nguyen P, Hernandez C, Bettencourt R, Ramirez K, Fortney L, et al. Magnetic resonance elastography vs transient elastography in detection of fibrosis and noninvasive measurement of steatosis in patients with biopsy-proven nonalcoholic fatty liver disease. Gastroenterology. 2017;152:598-607.e2.

31. Ajmera VH, Liu A, Singh S, Yachoa G, Ramey M, Bhargava $\mathrm{M}$, et al. Clinical utility of an increase in magnetic resonance elastography in predicting fibrosis progression in nonalcoholic fatty liver disease. Hepatology. 2020;71:849-60. 